\title{
Evidence for the importance of electrostatics in the function of two distinct families of ribosome inactivating toxins
}

\author{
ALEXEI V. KORENNYKH, ${ }^{1,2}$ CARL C. CORRELL, ${ }^{3,4}$ and JOSEPH A. PICCIRILLI ${ }^{1,2,3}$ \\ ${ }^{1}$ Department of Chemistry, The University of Chicago, Chicago, Illinois 60637, USA \\ ${ }^{2}$ Howard Hughes Medical Institute, The University of Chicago, Chicago, Illinois 60637, USA \\ ${ }^{3}$ Department of Biochemistry and Molecular Biology, The University of Chicago, Chicago, Illinois 60637, USA \\ ${ }^{4}$ Department of Biochemistry and Molecular Biology, Rosalind Franklin University of Medicine and Science, North Chicago, Illinois 60064, USA
}

\begin{abstract}
$\alpha$-Sarcin and ricin represent two structurally and mechanistically distinct families of site-specific enzymes that block translation by irreversibly modifying the sarcin/ricin loop (SRL) of 23S-28S rRNA. $\alpha$-Sarcin family enzymes are designated as ribotoxins and act as endonucleases. Ricin family enzymes are designated as ribosome inactivating proteins (RIP) and act as N-glycosidases. Recently, we demonstrated that basic surface residues of the ribotoxin restrictocin promote rapid and specific ribosome targeting by this endonuclease. Here, we report that three RIP: ricin A, saporin, and gypsophilin depurinate the ribosome with strong salt sensitivity and achieve unusually fast $k_{\text {cat }} / K_{m} \sim 10^{9}-10^{10} \mathrm{M}^{-1} \mathrm{~s}^{-1}$, implying that RIP share with ribotoxins a common mechanism of electrostatically facilitated ribosome targeting. Bioinformatics analysis of RIP revealed that surface charge properties correlate with the presence of the transport chain in the RIP molecule, suggesting a second role for the surface charge in RIP transport. These findings put forward surface electrostatics as an important determinant of RIP activity.
\end{abstract}

Keywords: ribosome; electrostatic; kinetics; mechanism; Smoluchowski; ribotoxin

\section{INTRODUCTION}

Restrictocin, an $\alpha$-sarcin-like ribotoxin from fungi, catalyzes endoribonucleolytic cleavage within the sarcin/ricin loop (SRL) of the large ribosomal subunit (Fig. 1A; Wool 1997). Basic surface residues located on restrictocin's active site face mediate Coulomb interactions with the ribosome and enhance the specificity and speed of the ribosome targeting (Korennykh et al. 2006). Electrostatic interactions give several characteristic features to the restrictocincatalyzed ribosome cleavage reaction that include (1) strong inverse dependence of the ribosome cleavage rate (and binding) on $\mathrm{KCl}$ concentration; (2) unusually rapid maximum $k_{\text {cat }} / K_{m}=1.7 \times 10^{10} \mathrm{M}^{-1} \mathrm{~s}^{-1}$; and (3) multiple

Reprint requests to: Joseph A. Piccirilli, Department of Biochemistry and Molecular Biology, and the Howard Hughes Medical Institute, The University of Chicago, 929 East 57th Street, CIS 406, Chicago, IL 60637, USA; e-mail: jpicciri@uchicago.edu; fax: (773) 702-0271; or Carl C. Correll, Department of Biochemistry and Molecular Biology, Rosalind Franklin University of Medicine and Science, 3333 Green Bay Road, North Chicago, IL 60064, USA; e-mail: carl.correll@rosalindfranklin.edu; fax: (847) 578-3240.

Article published online ahead of print. Article and publication date are at http://www.rnajournal.org/cgi/doi/10.1261/rna.619707. nonspecific restrictocin-binding sites on the ribosomal surface (Korennykh et al. 2006). These binding sites $(\sim 50)$ enhance the macroscopic association constant of the ribotoxin by about 50-fold, thereby maintaining saturating $\left(k_{\text {cat }}\right)$ conditions for restrictocin at in vivo salt and ribosome concentrations. These distinct electrostatic signatures together with the Poisson-Boltzmann calculations (Baker et al. 2001) imply that negative electrostatic potential covers much of the ribosomal surface. The negative electrostatic potential arises from both the negatively charged phosphodiester backbone and from conserved solvent-exposed acidic patches on ribosomal proteins, suggesting evolutionary conservation of the ribosome's overall electrostatics. This raises the possibility that electrostatic interactions may similarly facilitate ribosome targeting by proteins other than the $\alpha$-sarcin-like ribotoxins.

Here, we test this possibility experimentally with three ribosome-inactivating proteins (RIP) that are $\mathrm{N}$-glycosidases from plants: ricin A-chain, saporin, and gypsophilin. RIP share a common folded structure and catalyze SRL depurination at the adenosine adjacent to the $\alpha$-sarcin cleavage site, but have no sequence 
A.

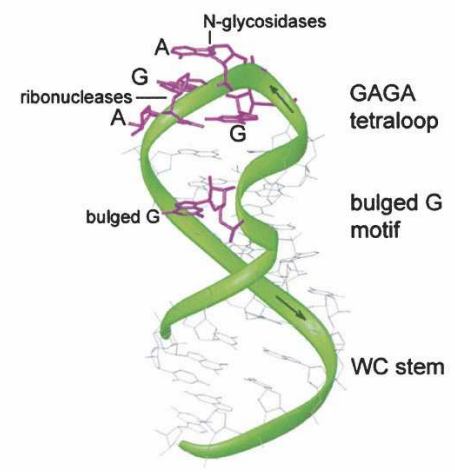

B.

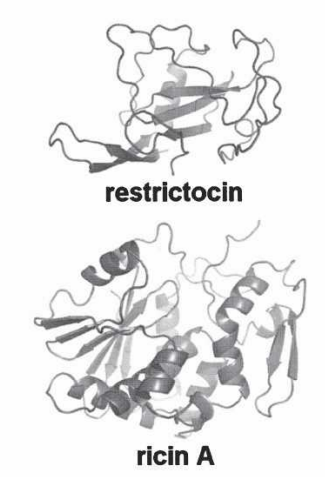

C.
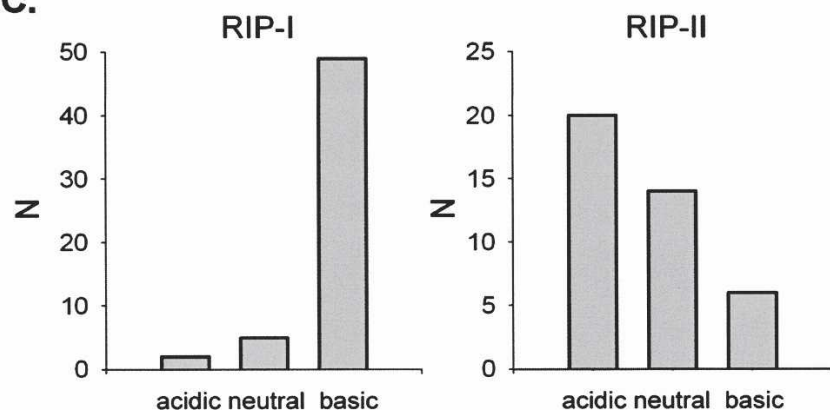

FIGURE 1. Location of the toxin target sites within SRL and comparison of the folded structures and isoelectric points of ribosome inactivating toxins. (A) Tertiary structure of the rat SRL RNA (PDB entry $430 \mathrm{D}$ ) showing the sites of cleavage by $\alpha$-sarcin-like ribonucleases and by $\mathrm{N}$-glycosidases. (B) Comparison of the tertiary structures of ribotoxin restrictocin and RIP ricin A. (C) Distribution of calculated isoelectric points within RIP-I and RIP-II toxins. Proteins were grouped in three categories shown by the three bars: acidic $\left(\mathrm{pI}_{\text {calc }} \leq 6\right)$, neutral $\left(6<\mathrm{pI}_{\text {calc }}<8\right)$, and basic $\left(\mathrm{pI}_{\text {calc }} \geq 8\right)$. The height of the bars $(N)$ corresponds to the number of RIP found within each group. Isoelectric points were calculated from polypeptide sequences (Materials and Methods).

or structural similarity with the $\alpha$-sarcin endonucleases (Fig. 1A,B; Supplemental Fig. 1). Therefore, plant $\mathrm{N}$-glycosidases provide suitable probes for testing whether electrostatic interactions are genuine to $\alpha$-sarcin ribotoxins or may extend more generally to protein-ribosome interactions. For ricin $\mathrm{A}$, the ribosome modification activity decreases upon chemical modifications of Arg residues lying outside the active site cleft (Watanabe et al. 1994) or upon site-directed mutagenesis of surface Arg residues (Marsden et al. 2004), consistent with the contribution of electrostatic contacts to the ricin activity against ribosomes. In light of our recent findings with restrictocin, it is appealing to suggest that ricin A employs these surface charges to target the ribosome via a mechanism similar to that of restrictocin. Accordingly, we analyzed the ribosome depurination reaction catalyzed by ricin A and two additional RIP using the quantitative framework developed previously during restrictocin studies (Korennykh et al. 2006).

\section{RESULTS AND DISCUSSION}

As an initial assessment of whether ricin-like N-glycosidases (plant and bacterial RIP) might exploit the electrostatic features of the ribosome, we examined calculated isoelectric points ( $\mathrm{pI}_{\text {calc }}$ ) of 96 unique RIP sequences from two RIP types: RIP-I and RIP-II (Supplemental Figs. 2, 3; Gasteiger et al. 2003). RIP-II contains two polypeptide chains, chains $\mathrm{A}$ and $\mathrm{B}$, linked by a disulfide bond. The A chain harbors the N-glycosidase activity for SRL depurination and shares sequence, structural homology, and active site composition with single-chain RIP-I toxins (Supplemental Fig. 1). The B chain enables receptor-mediated uptake of RIP-II toxins via retrograde transport along the secretory pathway and release of the catalytically active A chain into the cytoplasm (Wesche 2002; Stirpe 2004; Spooner et al. 2006). Our analysis revealed that RIP-I have isoelectric points predominantly in the basic $\mathrm{pH}$ range (Fig. 1C). In contrast, the catalytic A chains of RIP-II have isoelectric points that lie predominantly in the acidic and neutral pH range (Fig. 1C; Supplemental Fig. 2). As RIP-I and A chains of RIP-II share the same tertiary fold and mechanism of action on ribosomes (Marchant and Hartley 1995; Stirpe 2004), this trend apparently reflects adaptation for functional reasons. The significance of this adaptive trait remains unclear (Benner and Ellington 1988), although some toxins that violate this architectural imperative have weak toxic potency. For example, the RIP-I bouganin with $\mathrm{pI}_{\text {calc }}$ in the acidic range (Supplemental Fig. 2) exhibits poor cellular internalization and apparently has the lowest cytotoxicity among $\mathrm{N}$-glycosidases (den Hartog et al. 2002). Fusion of another RIP-I, momordin $\left(\mathrm{pI}_{\text {calc }}=9.3\right)$, to the ricin B-chain results in a chimeric toxin that undergoes inefficient cellular entry and has weaker toxic potency than that of native ricin (Sharma et al. 1999).

Recent studies have revealed significant differences in the cellular uptake routes for RIP-I and RIP-II molecules. Internalization of positively charged RIP-I such as saporin and gelonin occurs in a receptor-independent manner via fluid-phase endocytosis (Sandvig and van Deurs 2005; Vago et al. 2005), whereas receptor-dependent internalization of RIP-II toxins such as ricin or shiga toxin involves retrograde transport to the endoplasmic reticulum (ER), where protein disulfide isomerase (PDI) activates the toxins by releasing the B chain (Spooner et al. 2006). The differences between the two RIP types may reflect functional adaptation to their uptake routes. For example, proteins in the ER tend to have acidic pI values (Lucero et al. 1998; van Anken et al. 2003). The acidic or neutral pI of RIP-II molecules might impart a functional contribution to their ER localization to permit processing by PDI. In contrast, the basic charge of RIP-I may contribute to Golgi- and ER-independent endocytosis (Vives et al. 2003; Sandvig and van Deurs 2005; Vago et al. 2005).

To establish the role of electrostatic interactions in targeting the ribosome by the RIP, we examined ribosome 
cleavage reactions with RIP of both types. The sensitivity of the reaction rate to the salt concentration provides a wellestablished metric of electrostatic interactions. Accordingly, we acquired salt-rate profiles for RIP-I (saporin and gypsophilin) and RIP-II (ricin A) with ribosomes from rat liver (Fig. 2A). Saporin $\left(\mathrm{pI}_{\mathrm{calc}}=9.5\right)$ and gypsophilin $(\mathrm{pI}=10.1) \quad$ (Yoshinari et al. 1997) have basic isoelectric points and therefore represent the majority of RIP-I (Fig. 1C). Ricin A, the most studied N-glycosidase to date, has an isoelectric point in the median of $\mathrm{pI}_{\mathrm{calc}}$ distribution for RIP-II (Fig. 1C).

We determined the rates of $\mathrm{N}$-glycosidase-catalyzed depurination by following production of the $\sim 400$ nucle- otide (nt) long $\alpha$ fragment, generated via $\beta$ elimination within the SRL of $28 \mathrm{~S}$ rRNA and aniline cleavage of the abasic site (Fig. 2B,C; Materials and Methods). Similar to that of restrictocin, reaction profiles exhibited a strong linear dependence on $\mathrm{KCl}$ concentration in double-logarithmic coordinates $\left(n=\partial \log \left[k_{\text {cat }} / K_{m}\right] / \partial \log [\mathrm{KCl}]\right)$ in the 30-90 $\mathrm{mM}$ concentration range, suggesting that electrostatic interactions contribute to ribosome targeting by the three N-glycosidases. The salt dependence was significantly higher for saporin $\left(\mathrm{pI}_{\mathrm{calc}}=9.5, n=-5.2\right)$ and gypsophilin $(\mathrm{pI}=10.1, n=-5.2)$ than for ricin $\mathrm{A}\left(\mathrm{pI}_{\mathrm{calc}}=7.1, n=-2.5\right)$, indicating greater contribution of electrostatics to reactions with more cationic RIP. At $\sim 130 \mathrm{mM} \mathrm{KCl}$, the same
A

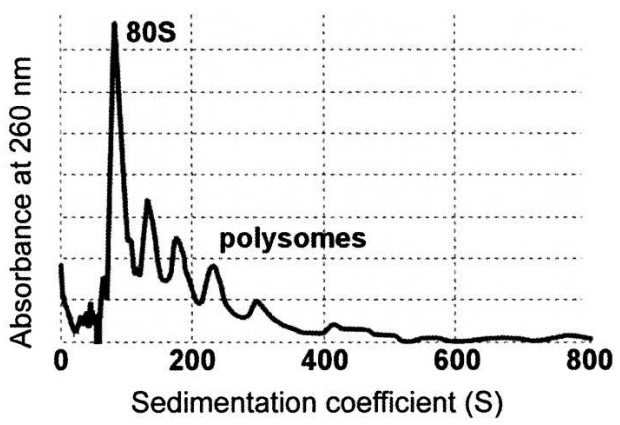

C

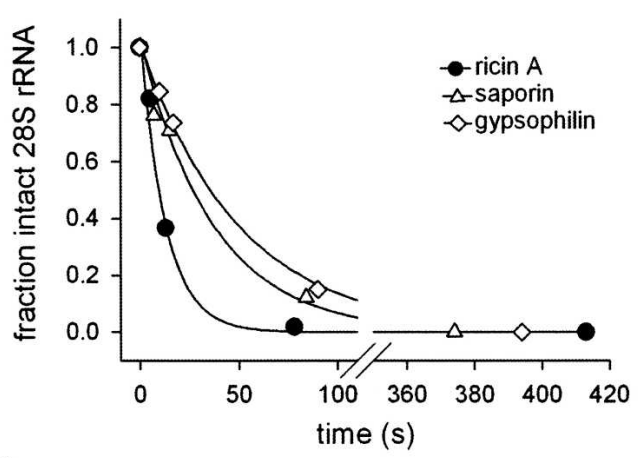

$\mathbf{E}$

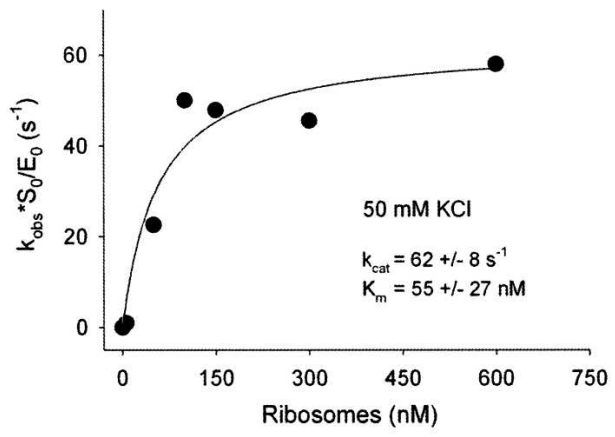

B

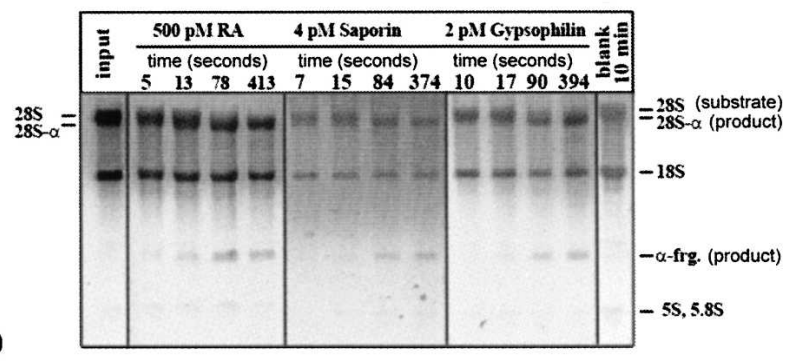

D

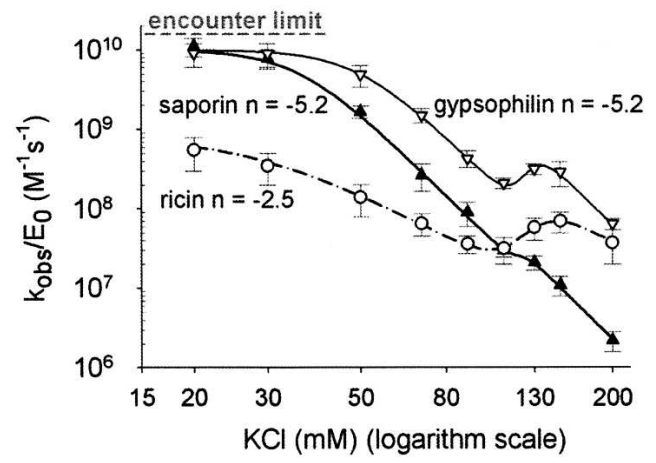

$\mathbf{F}$

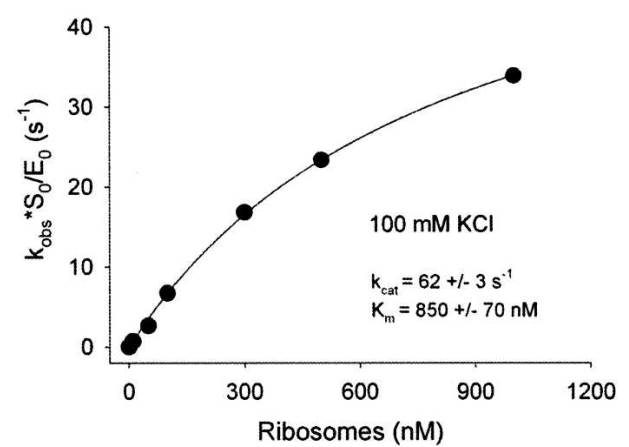

FIGURE 2. Sedimentation and RIP cleavage properties of ribosomes isolated from rat liver. (A) Sedimentation profile of rat liver ribosomes determined by analytical ultracentrifugation. $(B)$ Agarose gel electrophoresis analysis of ribosome cleavage by ricin A, saporin, and gypsophilin. $(C)$ Quantitation of the data in B. (D) Salt-rate profiles for cleavage of rat liver ribosomes by ricin A, saporin, and gypsophilin. The data were fit to a salt-dependent Michaelis-Menten equation (Materials and Methods). $(E, F)$ Measurement of kinetic constants $k_{\text {cat }}$ and $K_{m}$ for saporin-catalyzed ribosome cleavage at $50 \mathrm{mM} \mathrm{KCl}(E)$ and $100 \mathrm{mM} \mathrm{KCl}(F)$. 
cooperative stimulatory transition occurred in all three profiles (Fig. 2D; Hill coefficient $m=15 \pm 4$; Materials and Methods), as observed previously for restrictocin (Korennykh et al. 2006). This transition coincides with the appearance of free ribosomal subunits as monitored by analytical ultracentrifugation. At salt concentrations above the transition, the data fit to the pretransition slope $(n)$ for each $\mathrm{N}$-glycosidase, suggesting that the rearrangement in the ribosome does not alter the electrostatic interactions with RIP.

As the salt concentration decreases, the second-order rate constant $k_{\text {cat }} / K_{m}$ increases due to tighter binding of RIP to the ribosome (Fig. 2E,F). Finally, below $30 \mathrm{mM} \mathrm{KCl}$ saporin and gypsophilin cleave ribosomes with maximum $k_{\text {cat }} / K_{m}=(1 \pm 0.2) \times 10^{10} \mathrm{M}^{-1} \mathrm{~s}^{-1}$. This value approaches the encounter frequency predicted from the Smoluchowski equation, which estimates that diffusion-controlled encounters between saporin or gypsophilin and the ribosome occur with a frequency of $(1.8 \pm 0.4) \times 10^{10} \mathrm{M}^{-1} \mathrm{~s}^{-1}$ (Materials and Methods). Favorable electrostatic interactions provide the only known mechanism to allow binding at the encounter frequency (von Hippel and Berg 1989; Camacho et al. 1999; Selzer and Schreiber 1999; Selzer et al. 2000; Korennykh et al. 2006). Consistent with this view, the least positively charged RIP ricin A ( $\left.\mathrm{pI}_{\text {calc }}=7.1\right)$ exhibits a weaker salt dependence $(n=-2.5)$ and depurinates ribosomes with $k_{\text {cat }} / K_{m}$ not exceeding $7 \times 10^{8} \mathrm{M}^{-1} \mathrm{~s}^{-1}$ (Fig. 2D).

Gypsophilin exhibits the highest second order rate constant among the tested $\mathrm{N}$-glycosidases, at every salt concentration used. We estimate that SRL occupies $\sim 1 / 600$ of the ribosomal surface area (SRL size $\sim 20 \times 20 \AA$ A ribosome hydrodynamic radius $R_{h} \sim 140 \AA$; Nieuwenhuysen et al. 1983), suggesting that no more than one out of $\sim 600$ collisions between gypsophilin and the ribosome occurs with the enzyme active site directly encountering the SRL. In the absence of forces that would steer gypsophilin to the SRL prior to collision or allow long-lived diffusion of the RIP along the ribosomal surface subsequent to collision, $k_{\text {cat }} / K_{m}$ for ribosome depurination should not exceed $1.8 \times 10^{10} \mathrm{M}^{-1} \mathrm{~s}^{-1} / 600$, or $\sim 3 \times 10^{7} \mathrm{M}^{-1} \mathrm{~s}^{-1}$. The experimental $k_{\text {cat }} / K_{m}$ of gypsophilin considerably exceeds this basal value at all salt concentrations tested (Fig. 2D), suggesting that electrostatic interactions facilitate the diffusion of gypsophilin toward the SRL over a wide range of salt concentrations.

Our new data with three different RIP support the view that electrostatics has general importance for RIP function. We found unforeseen parallels in ribosome targeting by RIP of type-I and type-II and $\alpha$-sarcin endonucleases. All toxins that we have tested catalyze ribosome cleavage with a steep dependence on the salt concentration $(n)$ (Table 1), indicating that they exploit multiple electrostatic interactions with the ribosome. As a consequence, these enzymes can operate on the ribosome with $k_{\mathrm{cat}} / K_{m}$ exceeding their
TABLE 1. Kinetic parameters for cleavage of rat liver ribosomes by ricin $\mathrm{A}$, saporin, gypsophilin, and restrictocin at $50 \mathrm{mM} \mathrm{KCl}$, $1 \mathrm{mM} \mathrm{MgCl} 2,37^{\circ} \mathrm{C}$

\begin{tabular}{lcccc}
\hline & $\begin{array}{c}K_{m} \\
(\mathrm{nM})\end{array}$ & $\begin{array}{c}k_{\text {cat }} \\
\left(\mathrm{s}^{-1}\right)\end{array}$ & $\begin{array}{c}k_{\text {cat }} / K_{m} \\
\left(\mathrm{M}^{-1} \mathrm{~s}^{-1}\right)\end{array}$ & $n$ \\
\hline Ricin A & $2600^{\mathrm{a}}$ & $29.6^{\mathrm{a}}$ & $1.2 \times 10^{8}\left(1.0 \times 10^{7}\right)^{\mathrm{a}}$ & -2.5 \\
Saporin & 55 & 62 & $1.5 \times 10^{9}$ & -5.2 \\
Gypsophilin $^{\mathrm{b}}$ & - & - & $5.0 \times 10^{9}$ & -5.2 \\
Restrictocin $^{\mathrm{b}}$ & 30 & 1 & $3 \times 10^{7}$ & -6.0 \\
\hline
\end{tabular}

${ }^{a}$ Endo and Kunio (1988). Data were determined at $25 \mathrm{mM} \mathrm{KCl}$ and $5 \mathrm{mM} \mathrm{MgCl}_{2}$.

${ }^{\mathrm{b}}$ Korennykh et al. (2006).

basal encounter frequency of $\sim 3 \times 10^{7} \mathrm{M}^{-1} \mathrm{~s}^{-1}$ by more than an order of magnitude. Three toxins with basic $\mathrm{pI}_{\mathrm{cal}}$, restrictocin, saporin, and gypsophilin, achieve the Smoluchowski limit under low salt conditions, thereby rivaling the speed of the fastest enzyme, superoxide dismutase (SOD) (Folcarelli et al. 1999), except the toxins operate on a far larger and a more complex substrate than does SOD. Notably, restrictocin bears no sequence or structural similarity with the RIP, suggesting that structurally dissimilar proteins may exploit the electrostatics of the ribosome with the same efficiency. In conclusion, Coulomb interactions may have more general roles than previously anticipated in helping proteins to find their ribosomal target sites.

\section{MATERIALS AND METHODS}

\section{Bioinformatics}

The ExPasy protein server was use to identify 96 nonredundant RIP-I and RIP-II sequences and calculate their isoelectric points (Gasteiger et al. 2003).

\section{Analysis of salt dependence}

The salt-rate profiles for the ribosome depurination by ricin A, saporin and gypsophilin (Fig. 2D) were fit to a salt-dependent Michaelis-Menten equation obtained by replacing the singleturnover catalytic constant $k_{2}$ in the salt-dependent MichaelisMenten equation (Korennykh et al. 2006) with a sum

$$
k_{2}+a\left(\frac{[\mathrm{KCl}]^{m}}{K_{\text {trans }}^{m}+[\mathrm{KCl}]^{m}}\right)
$$

where $m$ accounts for the positive cooperative transition occurring at $\sim 130 \mathrm{mM} \mathrm{KCl}$. The variable $a$ is proportional to the amplitude of the transition and measures the sensitivity of a given RIP to the ribosome rearrangement occurring at $130 \mathrm{mM} \mathrm{KCl,} K_{\text {trans }}^{m}$ is the midpoint of the transition. The average values of $K_{\text {trans }}^{m}$ and $m$ were $130 \mathrm{mM}$ and 15 , respectively. The value of $a$ was 80 for saporin and 780 for ricin A and gypsophilin. 


\section{Encounter rate calculations}

The Smoluchowski encounter rate was calculated using Equation (2) (von Hippel and Berg 1989),

$$
k=4 \pi \mathrm{N}_{0}\left(R_{h}^{\mathrm{RIP}}+R_{h}^{\mathrm{Rb}}\right)\left(D_{h}^{\mathrm{RIP}}+D_{h}^{\mathrm{Rb}}\right) / 1000
$$

where $k$ is the bimolecular encounter rate constant $\left(\mathrm{M}^{-1} \mathrm{~s}^{-1}\right), \mathrm{N}_{0}$ is Avogadro's number, $R_{h}$ values are the hydrodynamic radii of RIP and the ribosome $(\mathrm{cm})$, and $D_{h}$ values are their diffusion coefficients $\left(\mathrm{cm}^{2} \mathrm{~s}^{-1}\right)$. Diffusion coefficients $D_{h}$ for the $80 \mathrm{~S}$ ribosome and saporin are $(1.3 \pm 0.3) \times 10^{-7} \mathrm{~cm}^{2} \mathrm{~s}^{-1}$ (Donceel et al. 1982; Nieuwenhuysen et al. 1983) and $1.33 \times 10^{-6} \mathrm{~cm}^{2} \mathrm{~s}^{-1}$ (Supplemental Fig. 4), respectively. Hydrodynamic radii $R_{h}$ are $(140 \pm 30) \times 10^{-6} \mathrm{~cm}$ for the $80 \mathrm{~S}$ particle (Nieuwenhuysen et al. 1983; Dube et al. 1998) and $24 \times 10^{-6} \mathrm{~cm}$ for saporin (Supplemental Fig. 4). Substitution of the corresponding $R_{h}$ and $D_{h}$ values in Equation (2) gives a bimolecular encounter rate constant $k$ of $(1.8 \pm 0.4) \times 10^{10} \mathrm{M}^{-1} \mathrm{~s}^{-1}$.

\section{Biophysical analyses}

To ensure that the $80 \mathrm{~S}$ particles were intact, analytical ultracentrifugation of ribosomes at different salt concentrations was performed on a Beckman XL-A, as described previously (Korennykh et al. 2006). Dynamic light scattering was performed on a PD-2020 dynamic light scattering detector. Experiments were conducted at the Biophysical Core facility of the University of Chicago. Before each run, the detector was calibrated with $2 \mathrm{mg}$ $\mathrm{mL}^{-1}$ of bovine serum albumin (Supplemental Fig. 4).

\section{Ribosome cleavage assay}

Saporin from Saponaria officinalis and ricin A chain from Ricinus communis were purchased from Sigma. Gypsophilin from Gypsophila elegans was a gift from Y. Endo (Ehime University, Matsuyama, Japan), Y.-L. Chan (University of Chicago), and I.G. Wool (University of Chicago). Ribosome cleavage reactions and data analysis were carried out as described previously for restrictocin (Korennykh et al. 2006). Briefly, reactions were conducted at $37^{\circ} \mathrm{C}$ and contained $10 \mathrm{mM}$ Tris. $\mathrm{HCl}(\mathrm{pH} 7.4)$, $0.05 \%(\mathrm{v} / \mathrm{v})$ Triton $\mathrm{X}-100, \mathrm{KCl}$ as indicated, $1 \mathrm{mM} \mathrm{MgCl}_{2}$, and 2$10 \mathrm{nM}$ ribosomes. Before gel analysis, samples of total rRNA were resuspended in $100 \mu \mathrm{L}$ of a 0.7:1 mixture of aniline and glacial acetic acid $(\mathrm{v} / \mathrm{v})$ and incubated at $37^{\circ} \mathrm{C}$ for $15 \mathrm{~min}$ to induce cleavage of rRNA backbone at the abasic site resulting from the Nglycosidase action. After incubation, rRNA was ethanol precipitated, dissolved in $10 \mathrm{M}$ urea loading solution, analyzed by $1.5 \%$ $(\mathrm{w} / \mathrm{v})$ agarose gel electrophoresis, and visualized by ethidium bromide staining. The cleavage of rRNA was quantified as described previously (Korennykh et al. 2006), by disappearance of the 28S band and by appearance of the $\alpha$ fragment, using the $18 \mathrm{~S}$ rRNA and $5 \mathrm{~S}+5.8 \mathrm{~S}$ bands as internal standards. The Nglycosidases examined cleaved $28 \mathrm{~S}$ rRNA to greater than $90 \%$ completion with single exponential kinetics.

\section{Experimental errors}

All kinetic values were determined multiple times. Experimental errors are included in the text where appropriate.

\section{SUPPLEMENTAL DATA}

All Supplementary Figures and materials can be obtained at http:// netcpp.com/2007/RNA/Toxins_Suppl.pdf or by e-mail: avkorenn@ alumni.uchicago.edu.

\section{ACKNOWLEDGMENTS}

We thank Professors Y. Endo, I. Wool, and Dr. Yuen-Ling Chan for the gift of gypsophilin and valuable discussions; Dr. Eelco van Anken for review and important comments on the manuscript; and Jose M. Olvera for technical assistance. We thank members of the Piccirilli and Correll laboratory for helpful comments on the manuscript. This work was supported by grants to A.V.K. from the Burroughs Wellcome Fund (ID 1001774), to J.A.P. from Howard Hughes Medical Institute, and to C.C.C. from the National Institutes of Health (GM59782).

Received May 7, 2007; accepted June 9, 2007.

\section{REFERENCES}

Baker, N.A., Sept, D., Joseph, S., Holst, M.J., and McCammon, J.A. 2001. Electrostatics of nanosystems: Application to microtubules and the ribosome. Proc. Natl. Acad. Sci. 98: 10037-10041.

Benner, S. and Ellington, A.D. 1988. Interpreting the behavior of enzymes: Purpose or pedigree? CRC Crit. Rev. Biochem. 23: 369-426.

Camacho, C.J., Weng, Z., Vajda, S., and DeLisi, C. 1999. Free energy landscapes of encounter complexes in protein-protein association. Biophys. J. 76: 1166-1178.

den Hartog, M.T., Lubelli, C., Boon, L., Heerkens, S., Ortiz Buijsse, A.P., de Boer, M., and Stirpe, F. 2002. Cloning and expression of cDNA coding for bouganin. Eur. J. Biochem. 269: 1772-1779.

Donceel, K., Nieuwenhuysen, P., and Clauwaert, J. 1982. The size and conformation of Artemia (brine-shrimp) ribosomal RNA free in solution. Biochem. J. 205: 495-501.

Dube, P., Wieske, M., Stark, H., Schatz, M., Stahl, J., Zemlin, F., Lutsch, G., and van Heel, M. 1998. The 80 S rat liver ribosome at $25 \AA$ resolution by electron cryomicroscopy and angular reconstitution. Structure 6: 389-399.

Endo, Y. and Kunio, T. 1988. The RNA N-glycosidase activity of ricin A-chain. The characteristics of the enzymic activity of ricin A-chain with ribosomes and with rRNA. J. Biol. Chem. 263: 8735-8739.

Folcarelli, S., Venerini, F., Battistoni, A., O’Neill, P., Rotilio, G., and Desideri, A. 1999. Toward the engineering of a super efficient enzyme. Biochem. Biophys. Res. Commun. 256: 425-428.

Gasteiger, E., Gattiker, A., Hoogland, C., Ivanyi, I., Appel, R.D., and Bairoch, A. 2003. ExPASy: The proteomics server for in-depth protein knowledge and analysis. Nucleic Acids Res. 31: 37843788.

Korennykh, A.V., Piccirilli, J.A., and Correll, C.C. 2006. The electrostatic character of the ribosomal surface enables extraordinarily rapid target location by ribotoxins. Nat. Struct. Mol. Biol. 13: 436-443.

Lucero, H.A., Lebeche, D., and Kaminer, B. 1998. ERcalcistorin/ protein-disulfide isomerase acts as a calcium storage protein in the endoplasmic reticulum of a living cell. Comparison with calreticulin and calsequestrin. J. Biol. Chem. 273: 9857-9863.

Marchant, A. and Hartley, M.R. 1995. The action of pokeweed antiviral protein and ricin A-chain on mutants in the $\alpha$-sarcin loop of Escherichia coli 23 S ribosomal RNA. J. Mol. Biol. 254: $848-855$. 
Marsden, C.J., Fulop, V., Day, P.J., and Lord, J.M. 2004. The effect of mutations surrounding and within the active site on the catalytic activity of ricin A chain. Eur. J. Biochem. 271: 153-162.

Nieuwenhuysen, P., Clauwaert, J., Ledoigt, G., and Curgy, J.J. 1983. Structural differences between ribosomes of various eukaryotes: Stability, density, mass, size and structure in solution of cytoplasmic ribosomes from Tetrahymena, Artemia and Euglena. Int. J. Biol. Macromol. 5: 361-365.

Sandvig, K. and van Deurs, B. 2005. Delivery into cells: Lessons learned from plant and bacterial toxins. Gene Ther. 12: 865872.

Selzer, T. and Schreiber, G. 1999. Predicting the rate enhancement of protein complex formation from the electrostatic energy of interaction. J. Mol. Biol. 287: 409-419.

Selzer, T., Albeck, S., and Schreiber, G. 2000. Rational design of faster associating and tighter binding protein complexes. Nat. Struct. Biol. 7: 537-541.

Sharma, S., Podder, S.K., and Karande, A.A. 1999. Comparative studies on kinetics of inhibition of protein synthesis in intact cells by ricin and a conjugate of ricin B-chain with momordin. Mol. Cell. Biochem. 200: 133-141.

Spooner, R.A., Smith, D.C., Easton, A.J., Roberts, L.M., and Lord, J.M. 2006. Retrograde transport pathways utilised by viruses and protein toxins. Virol J. 3: 26.

Stirpe, F. 2004. Ribosome-inactivating proteins. Toxicon 44: 371383.
Vago, R., Marsden, C.J., Lord, J.M., Ippoliti, R., Flavell, D.J., Flavell, S.U., Ceriotti, A., and Fabbrini, M.S. 2005. Saporin and ricin A chain follow different intracellular routes to enter the cytosol of intoxicated cells. FEBS J. 272: 4983-4995.

van Anken, E., Romijn, E.P., Maggioni, C., Mezghrani, A., Sitia, R., Braakman, I., and Heck, A.J. 2003. Sequential waves of functionally related proteins are expressed when B cells prepare for antibody secretion. Immunity 18: 243-253.

Vives, E., Richard, J.P., Rispal, C., and Lebleu, B. 2003. TAT peptide internalization: Seeking the mechanism of entry. Curr. Protein Pept. Sci. 4: 125-132.

von Hippel, P.H. and Berg, O.G. 1989. Facilitated target location in biological systems. J. Biol. Chem. 264: 675-678.

Watanabe, K., Dansako, H., Asada, N., Sakai, M., and Funatsu, G. 1994. Effects of chemical modification of arginine residues outside the active site cleft of ricin A-chain on its RNA N-glycosidase activity for ribosomes. Biosci. Biotechnol. Biochem. 58: 716-721.

Wesche, J. 2002. Retrograde transport of ricin. Int. J. Med. Microbiol. 291: 517-521.

Wool, I.G. 1997. Structure and mechanism of action of the cytotoxic ribonuclease $\alpha$-sarcin. Academic Press, Inc., San Diego.

Yoshinari, S., Koresawa, S., Yokota, S., Sawamoto, H., Tamura, M., and Endo, Y. 1997. Gypsophilin, a new type 1 ribosome-inactivating protein from Gypsophila elegans: Purification, enzymatic characterization, and subcellular localization. Biosci. Biotechnol. Biochem. 61: 324-331. 

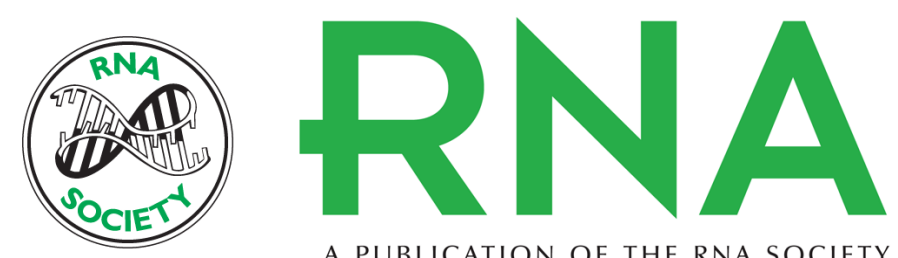

A PUBLICATION OF THE RNA SOCIETY

\section{Evidence for the importance of electrostatics in the function of two distinct families of ribosome inactivating toxins}

Alexei V. Korennykh, Carl C. Correll and Joseph A. Piccirilli

RNA 2007 13: 1391-1396 originally published online July 12, 2007

Access the most recent version at doi:10.1261/rna.619707

\section{References This article cites 27 articles, 5 of which can be accessed free at:} http://rnajournal.cshlp.org/content/13/9/1391.full.html\#ref-list-1

Open Access Freely available online through the RNA Open Access option.

License Freely available online through the open access option.

Email Alerting Receive free email alerts when new articles cite this article - sign up in the box at the Service top right corner of the article or click here. 